\title{
Use of Acetate for the Management of Patients with Staphylococcus Aureus Sepsis
}

\author{
Dario Fernando Muñoz Mora ${ }^{1 *}$, Jhon Fredy Bello Cordero² ${ }^{2}$ Fernán Andrés Torres Hernández ${ }^{3}$, \\ Estivinson Reverol Padilla4, Decknia Luz Vásquez Moris ${ }^{5}$, Jorge Eduardo Montes Argumedo ${ }^{6}$, \\ Edmundo Alberto Molina Álvarez ${ }^{7}$, Ader Andrés Vergara Álvarez ${ }^{8}$, and Daniel José Díaz Cortés ${ }^{9}$ \\ ${ }^{1}$ Physician and Surgeon, Epidemiology Specialist, Universidad del Cauca y Universidad Autónoma de Bucaramanga, Colombia \\ ${ }^{2}$ Physician Specializing in Emergency Medicine, Fundación Universitaria de Ciencias de la Salud, Bogotá-Colombia \\ ${ }^{3}$ General physician, Universidad de Cartagena, Colombia \\ ${ }^{4}$ General physician, Universidad Cooperativa de Colombia sede Santa Marta, Colombia \\ ${ }^{5}$ General physician, Universidad Libre de Barranquilla, Colombia \\ ${ }^{6}$ General physician, Universidad del Norte, Colombia \\ ${ }^{7}$ General physician, Universidad del Norte, Barranquilla, Colombia \\ ${ }^{8}$ General physician, Universidad Libre Seccional Barranquilla, Colombia \\ ${ }^{9}$ General physician, Universidad Libre de Cali, Colombia
}

*Corresponding author: Dario Fernando Muñoz Mora, Physician and Surgeon, Epidemiology Specialist, Universidad del Cauca y

Universidad Autónoma de Bucaramanga, Colombia

\section{ARTICLE INFO}

Received: 㓞 November 01, 2021

Published: November 15, 2021

Citation: Dario Fernando Muñoz Mora, Jhon Fredy Bello Cordero, Fernán Andrés Torres Hernández, Estivinson Reverol Padilla, Juan Farak Gomez, et al., Use of Acetate for the Management of Patients with Staphylococcus Aureus Sepsis. Biomed J Sci \& Tech Res 40(1)-2021. BJSTR. MS.ID.006386.

\section{ABSTRACT}

Staphylococcus aureus is an opportunistic pathogen that normally colonizes the anterior nostrils of humans. Sepsis is one of the most common critical care problems with high morbidity and mortality, it is the main cause of acute kidney injury. Intravenous fluids are the mainstay of treatment in patients with hypovolemia due to severe sepsis, we currently have colloid and crystalloid solutions for the management of electrolyte therapy. We can highlight the use of sodium acetate; this acts through the Grp43 receptor where it causes apoptosis of neutrophils and therefore the resolution of inflammation.

Keywords: Staphylococcus Aureus; Sepsis; Acetate

\section{Introduction}

Staphylococcus aureus is an opportunistic pathogen that normally colonizes the anterior nostrils of humans, it is one of the most frequent causes of local infections in the skin, where it becomes an entrance to the deeper tissues, where it could give rise to infections fatalities such as sepsis and / or endocarditis [1]
Sepsis is the systemic inflammatory response to infection. There are risk factors associated with Staphylococcus aureus sepsis, advanced age, infants, the presence of additional comorbidities such as diabetes, kidney disease, HIV infection, presence of medical devices, application of parenteral drugs Staphylococcus aureus 
produces clearance from the bloodstream by the immune system, and how this pathogen hijacks the host's coagulation and defense systems and interacts more with the endothelium of blood vessels where the vessel wall allows the invading pathogen to directly damage the endothelium for its secreted toxins, such as alpha-toxin and superantigens that activate the endothelium, further increasing endothelial dysfunction, aberrant clotting, and vascular leakage [1] The annual incidence of sepsis caused by this pathogen has been increasing in recent years is 4.31 to 38.22 per 100,000 person years in the United States. Their mortality can be $20 \%$ despite treatment [2] In the management of fluid resuscitation plays an important role the emergence of the use of crystalloid solutions have predictive benefits and effects on the health of the patient The objective of our work is to analyze acetate management in patients with Staphylococcus aureus septicemia.

\section{Methodology}

A detailed bibliographic search of information published in the databases pubmed, Elsevier, scielo, national and international libraries is carried out. The following descriptors were used Staphylococcus aureus, sepsis, acetate. The search for articles was carried out in Spanish and English, it was not limited by year of publication.

\section{Results}

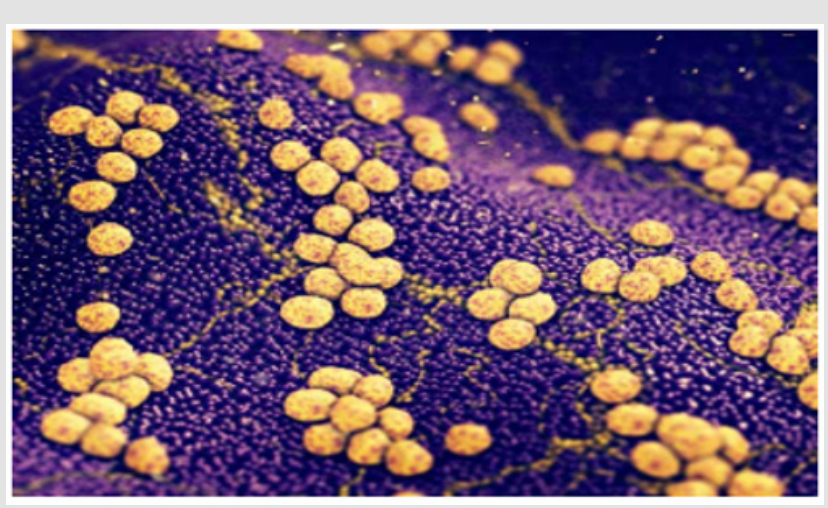

Figure 1: Staphylococcus aureus in clusters.

Staphylococcus are a large group of gram positive bacteria, these are distinguished by their groupings that resemble bunches of grapes (Figure 1), this genus of bacteria is characterized by its great adaptability and easy spread [3]. Staphylococcus aureus is part of the normal human flora, between 25 and $50 \%$ of the healthy population is colonized by this bacterium, constituting a risk due to its dissemination [4] The pathogenicity of the Staphylococcus aureus species is related to the components of its surface, the pathogenesis caused by the microorganism is due to the decrease in host immunity and virulence factors (that is, the ability to inflict damage to the Guest) [1]. They are the most frequent cause of infections in the skin and soft tissues, the majority are usually selflimited although sometimes it becomes the pathway of entry of the pathogen to deeper tissues and the bloodstream, the presence of Staphylococcus aureus in the bloodstream can lead to sepsis where there is an immunosuppressive response accompanied by inflammation.

In the human body, there is a series of defense mechanisms at the time when staphylococcus aureus enters the bloodstream, it is initially eliminated by the kupffer cells (hepatic macrophages) this process occurs with the help of circulating platelets that they do is bind to the surface of the macrophage, enclosing it for the phagocytization process to be effective. There are strains of Staphylococcus aureus that can evade this process, they can survive and multiply in the macrophage, becoming a source of dissemination [1]. The second line of defense of phagocytosis is activated portal circulation neutrophils, where a small percentage of bacteria can survive intracellularly, thus giving a systemic spread [1]. Later in staphylococcus aureus sepsis, there is an activation of prothrombin and other clotting factors, by the bacteria binding to fibrinogen and using it to cross-link individual cells to form large fibrinogen-coated clumps [1].

Endoletial damage occurs, the microorganism has the ability to adhere to the endothelium, this allows the invading pathogen to directly damage the wall of the vessel by its secreted toxins, such as alpha-toxin and superantigens that activate the endothelium, which further increases dysfunction endothelial, aberrant coagulation and vascular leak [1] Sepsis is one of the most common critical care problems with high morbidity and mortality, it is the main cause of acute kidney injury. Treatment must be essential for the patient to lead to improvement and have less risk and adverse effects [5]. Intravenous fluids are the mainstay of treatment in patients with hypovolemia due to severe sepsis, we currently have colloid and crystalloid solutions for the management of electrolyte therapy. But a controversy has arisen in which we should use, which will bring the best benefit for these patients [5]. Colloids such as dextrans, hydroxyethyl starch, are plasma volume expanders and have been associated with adverse effects such as renal failure with the need for renal replacement techniques, even increasing the risk of death. On the other hand, we found that crystalloid solutions such as Ringer's Acetate, a clinical benefit with crystalloid is demonstrated in various studies, they contain less concentration of chlorine and sodium $[6,7]$.

\section{Discussion}

It has been shown that part of the action of acetate can occur through the activation of the G-protein-coupled receptor, Gpr43 [8]. These receptors are commonly activated by short-chain fatty acids acetate, propionate and butyrate, ligands that originate from 
bacteria. anaerobic in the intestine as by-products of fermentation [9], the activation of these receptors allows neutrophils to trigger an antimicrobial response after an additional pro-inflammatory stimulation [10], in addition, the increase in the expression of GPR43 in blood cells is related to a longer survival of septic patients [11]. Through acetate treatment, neutrophils are prepared in a GPR43-dependent manner, leading to increased neutrophil chemotaxis, bacterial death, and better resolution of inflammation and the outcome of sepsis [12]. A study reported that through the action of Gpr43, the apoptosis of neutrophils was induced and the resolution of inflammation, it was also evidenced that acetate regulates acute inflammation by promoting caspase-dependent apoptosis of neutrophils, efferocytosis and leading to a decrease in the inflammatory process inflammation. Resolution of neutrophilic inflammation was associated with decreased NF- $\kappa$ B activity and increased production of anti-inflammatory mediators, including IL10 , TGF- $\beta$, and annexin A1 [8].

\section{Conclusion}

Staphylococcus aureus sepsis has a high incidence, mortality, and morbidity rate. Currently there are new drug therapies that can help to have a better evolution of those who suffer from it, where we can highlight the use of sodium acetate; This acts through the Grp43 receptor where it causes apoptosis of neutrophils and therefore the resolution of inflammation. Its use should be more implemented.

\section{References}

1. Kwiecinski JM, Horswill AR (2020) Staphylococcus aureus bloodstream infections: pathogenesis and regulatory mechanisms. Current Opinion in Microbiology 53: 51-60.

\section{ISSN: 2574-1241}

DOI: $10.26717 /$ BJSTR.2021.40.006386

Juan Farak Gomez. Biomed J Sci \& Tech Res

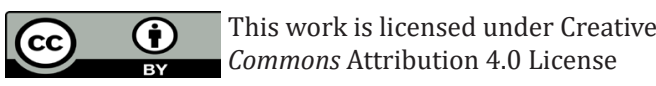

Submission Link: https://biomedres.us/submit-manuscript.php
2. Holland TL, Arnold C, Fowler VG (2014) Clinical Management of Staphylococcus aureus Bacteremia A Review. JAMA 312(13): 1330-1341.

3. Zendejas-Manzo GS, Avalos-Flores H, Soto-Padilla MY (2014) Microbiología general de Staphylococcus aureus: Generalidades, patogenicidad y métodos de identificación. Revista Biomédica. Rev Biomed 25(3): 129-143.

4. Cervantes-García E, García-González R, Salazar-Schettino PM (2014) Características generales del Staphylococcus aureus. Rev Latinoam Patol Clin Med Lab 61(1): 28-40.

5. Liu F, Zhan J, Zhu Y, Su L, Li Y, et al. (2021) Acetate Ringer's solution versus $0.9 \%$ saline for septic patients: study protocol for a multi-center parallel controlled trial. Trials 22: 89.

6. Perner A, Haase N, Guttormsen AB, Tenhunen J, Klemenzson G, et al. (2012) Hydroxyethyl Starch 130/0.42 versus Ringer's Acetate in Severe Sepsis. original article. The New England Journal of Medicine 367(2): 124-134.

7. Schlatterer K, Beck C, Schoppmeier U, Peschel A, Kretschmer D (2021) Acetate sensing by GPR43 alarms neutrophils and protects from severe sepsis. COMMUNICATIONS BIOLOGY 4: 928.

8. Vieira AT, Galvão I, Macia LM, Sernaglia EM, Vinolo MAR, et al. (2016) Dietary fiber and the short-chain fatty acid acetate promote resolution of neutrophilic inflammation in a model of gout in mice. Jlb 101(1): 275284.

9. Bolognini D, Tobin AB, Milligan G, Moss CE (2015) The Pharmacology and Function of Receptors for Short-Chain Fatty Acids. The American Society for Pharmacology and Experimental Therapeutics 89(3): 388398.

10. El-Benna J, et al. (2016) Cebado del estallido respiratorio de neutrófilos: papel en la defensa y la inflamación del huésped Immunol Rev 273: 180193.

11. Carr ZJ y col (2018) El aumento de la expresión del receptor FFA2 / GPR43 en sangre completa se asocia con un aumento de la supervivencia a 30 días en pacientes con sepsis. BMC Res Notas 11: 41.

12. Schlatterer K, Beck C, Schoppmeier U, Peschel A, Kretschmer D (2021) Acetate sensing by GPR 43 alarms neutrophils and protects from severe sepsis. Communications Biology.

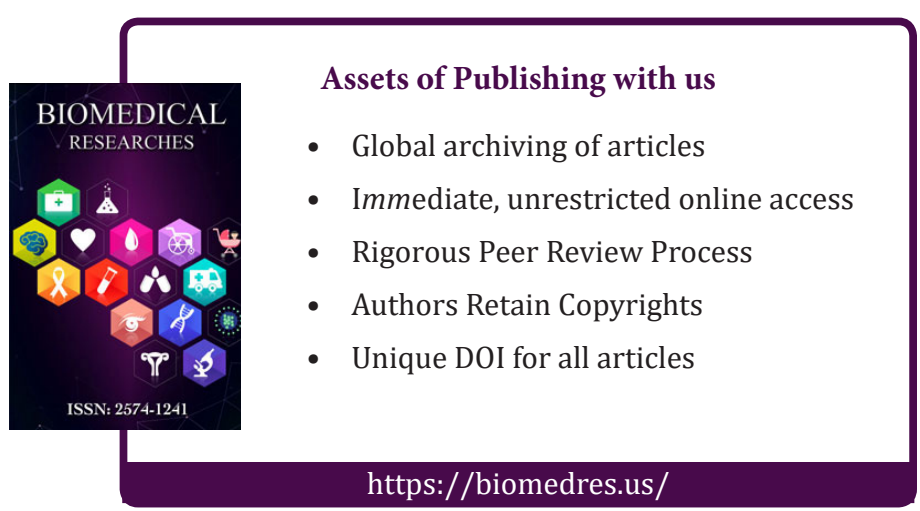

